\title{
Molecular characterization of a rare G1P[19] rotavirus strain from India: evidence of reassortment between human and porcine rotavirus strains
}

Correspondence

Shobha D. Chitambar

chitambars@hotmail.com

Received 14 May 2009

Accepted 9 August 2009

\author{
Shobha D. Chitambar, Ritu Arora and Preeti Chhabra \\ Enteric Viruses Department, National Institute of Virology, Pune 411001, India
}

\section{INTRODUCTION}

Group A rotaviruses of the family Reoviridae are recognized as the single most common cause of non-bacterial acute gastroenteritis. The viral genome consists of 11 segments of dsRNA ranging from 0.6 to $3.3 \mathrm{~kb}$, which encode six structural (VP1-4, VP6 and VP7) and six non-structural (NSP1-6) proteins (Estes, 2001). A dual classification system based on two outer-layer proteins, VP7 and VP4, has been established for rotaviruses. In recent years, the application of molecular methods has allowed the identification of $20 \mathrm{G}$ and $28 \mathrm{P}$ types in human and animal rotavirus infections (Solberg et al., 2009). Ten G and $11 \mathrm{P}$ types have been detected in human infections, although five $\mathrm{G}(\mathrm{G} 1-4$ and $\mathrm{G} 9)$ and two $\mathrm{P}(\mathrm{P}[4]$ and $\mathrm{P}[8])$ types are found most commonly (Santos \& Hoshino, 2005; Grimwood \& Kirkwood, 2008; Matthijnssens et al., 2008).

The middle-layer protein, VP6, determines the rotavirus group and subgroup (SG) specificities. More recently, on the basis of the NSP4 gene, rotaviruses have been classified into six genotypes: A (prototype strain KUN), B (Wa), C (AU-1), D (EW), E (avian-like) and F (Ch-1) (Horie et al., 1997; Ciarlet et al., 2000; Ito et al., 2001; Mori et al., 2002; Matthijnssens et al., 2008).

Surveillance of rotavirus strains in the human population has revealed variation in the distribution of $G$ and $P$

Abbreviation: SG, subgroup.

The GenBank/EMBL/DDBJ accession numbers for the sequences determined in this study are D0886957 (VP7), D0887060 (VP4), FJ685614 (VP6) and FJ685615 (NSP4). genotypes, together with the emergence of unusual G/P combinations in different geographical locations (Gentsch et al., 2005; Santos \& Hoshino, 2005). Many such genotypes have been found in regions where animals live in close proximity to humans (Urasawa et al., 1992). Human group A rotavirus strains, which carry genes commonly found in animal rotaviruses, have been isolated from infected children in both developed and developing countries. There is increasing evidence to demonstrate a significant contribution of animal rotaviruses in giving rise to reassortment and genetic diversity among human rotavirus strains (Varghese et al., 2004; Maneekarn et al., 2006). The possibility of the reassortant strains upholding their virulence in both species has been also described on account of genetic similarity between animal and human rotavirus strains (Nakagomi et al., 1990; Urasawa et al., 1992). In this context, porcine rotavirus genes VP4, VP6, NSP1, NSP3 and NSP4 have been reported to have a close relationship with their counterparts in human rotaviruses, and hence porcine rotaviruses are considered a potential source of interspecies rotavirus infection (Martella et al., 2005).

The present study reports the characterization of a rotavirus strain with an unusual specificity of human VP7 (G1) and porcine VP4 (P[19]) genes identified in a rotavirus surveillance study conducted among children with diarrhoea (Zade et al., 2009).

\section{METHODS}

Specimen. The rotavirus strain NIV929893 was isolated from a faecal specimen collected from an 11-month-old male patient 
hospitalized for acute gastroenteritis in Pune, western India, in July 1992. The specimen was collected within $24 \mathrm{~h}$ of hospitalization with prior informed consent from the parents. A $10 \%$ faecal suspension was prepared in $0.01 \mathrm{M}$ PBS ( $\mathrm{pH} 7.4$ ) and rotavirus positivity was identified by antigen-capture ELISA (IDEIA Rotavirus; Dako). The specimen was stored in aliquots at $-20{ }^{\circ} \mathrm{C}$ until analysed.

RNA extraction and RT-PCR. Viral RNA was extracted from a $30 \%$ faecal suspension using Trizol LS Reagent (Invitrogen) according to the manufacturer's instructions. RT-PCR was carried out for fulllength VP7 (1062 bp), VP4 (2359 bp), VP6 (1356 bp) and NSP4 (752 bp) genes using a One-step RT-PCR kit (Qiagen) and primers specific for each of the genes (Table 1). The PCR conditions involved an initial reverse transcription step of $30 \mathrm{~min}$ at $45{ }^{\circ} \mathrm{C}$, followed by PCR activation at $95{ }^{\circ} \mathrm{C}$ for $15 \mathrm{~min}, 40$ cycles of amplification ( $1 \mathrm{~min}$ at $94{ }^{\circ} \mathrm{C}, 1 \mathrm{~min}$ at $45^{\circ} \mathrm{C}$ and $2.5 \mathrm{~min}$ at $70{ }^{\circ} \mathrm{C}$ ) and a final extension of $7 \mathrm{~min}$ at $70{ }^{\circ} \mathrm{C}$. All of the PCR products were electrophoresed in $2 \%$ agarose gels containing ethidium bromide $\left(0.5 \mu \mathrm{g} \mathrm{ml}^{-1}\right)$ and visualized under a UV transilluminator.

Nucleotide sequencing and phylogenetic analyses. The PCR amplicons were excised from the gel for purification (QIAquick Gel Extraction kit; Qiagen). Sequencing was carried out using a BigDye Terminator v3.1 Cycle Sequencing kit (Applied Biosystems) and the sequence data were collected using an ABI 3130XL automated sequencer (Applied Biosystems). Multiple alignments were carried out using CLUSTAL w (Thompson et al., 1994). Phylogenetic analyses were conducted using the MEGA v3.1 software program (Kumar et al., 2004). The statistical significance of the relationships was estimated by bootstrap resampling analysis (1000 replications).

\section{RESULTS}

\section{Sequence analysis of the VP7 gene}

Phylogenetically, the VP7 gene of rotavirus strain NIV929893 segregated with the G1 genetic cluster, which contained the prototype strains $\mathrm{KU}$ and $\mathrm{Wa}$, as well as other G1 strains from Pune, India, detected in human infections (Fig. 1a). Nucleotide and amino acid sequence identities were $92.0-99.9 \%$ and $95.7-100 \%$, respectively. The strain showed only $73.0-76.2 \%$ nucleotide and $75.8-79.8 \%$ amino acid identity with selected strains of other G types (Table 2).

\section{Sequence analysis of the VP4 gene}

The VP4 gene of strain NIV929893, when analysed phylogenetically, clustered with $\mathrm{P}[19]$ rotavirus strains indicating a porcine origin (Fig. 1b). The nucleotide and deduced amino acid sequences showed $96.2-97.4 \%$ and 97-98.8\% identities, respectively, with Mc323, Mc345, RMC/G60, RMC321 and RMC/G7 strains of P[19] specificity and only $71.8-77.2 \%$ and $59.7-73.6 \%$ nucleotide and amino acid identities with selected strains of other $\mathrm{P}$ genotypes (Table 2).

\section{Sequence analysis of the VP6 gene}

Comparative analysis of the sequences of the VP6 gene of strain NIV929893 showed $92.3-92.8 \%$ nucleotide and 98.2-99\% amino acid identities with human rotavirus strains Dhaka12-03, Matlab13-03, RMC100 and RMC437, and $81.2-82.3 \%$ and $93.5-93.7 \%$ nucleotide and amino acid identities, respectively, with porcine rotavirus strains OSU and YM (Fig. 2a, Table 2). The strain was placed in SGII on the basis of amino acid residues at positions 248 (Phe), 305 (Asn), 306 (Ala), 310 (Gln) and 315 (Gln) of VP6, which are all conserved in SGII rotaviruses (Greig et al., 2006).

\section{Sequence analysis of the NSP4 gene}

The nucleotide and corresponding amino acid sequences of the NSP4 gene of strain NIV929893 were compared with those of rotavirus strains representing genotypes A-F. Phylogenetically, the NSP4 gene of strain NIV929893 grouped with genotype $\mathrm{B}$ and was closely related to the NSP4 gene of rotavirus strain RMC/G7 with 98.4 and 99.4\% nucleotide and amino acid identities, respectively, indicating porcine origin (Fig. 2b, Table 2). However, nucleotide and amino acid identities with genotype $\mathrm{B}$ strains of human origin were $88.8-89.4 \%$ and $90.9-93.7 \%$. With the other genotypes - A, C, D, E and F - the nucleotide and amino acid identities were $78.9-82.6 \%$ and $81.7-85.7 \%, 77.3-80.9 \%$ and $82.3-82.9 \%, 66.7-67.2 \%$ and $62.9-64 \%, 49.8-51.9 \%$ and $29-31.4 \%$, and $50.5 \%$ and $31.5 \%$, respectively.

\section{DISCUSSION}

Group A rotaviruses are the most common cause of diarrhoea in humans and animals. Rotaviruses are

Table 1. List of primers used in this study

\begin{tabular}{|c|c|c|c|}
\hline Gene & Primer name & Primer sequence $\left(5^{\prime} \rightarrow 3^{\prime}\right)$ & Reference \\
\hline \multirow[t]{2}{*}{ VP7 } & $\mathrm{C} 2$ & GGCTTTAAAAGAGAGAATTTCCGTCTGG & Gouvea et al. (1990) \\
\hline & $\mathrm{C} 1$ & GGTCACATCATACAATTCTAATCTAAG & Gouvea et al. (1990) \\
\hline \multirow[t]{2}{*}{ VP4 } & VP4, Gen F & GGCTATAAAATGGCTTCGCTCA & Matthijnssens et al. (2006) \\
\hline & VP4, Gen R & GGTCACATCCTCAATAGCGTTCT & Matthijnssens et al. (2006) \\
\hline \multirow[t]{2}{*}{ VP6 } & VP6-R1F & GGTCACATCCTCAATAGCGTTCT & This study \\
\hline & VP6-1366R & GGCTTTTAAACGAAGTCTTC & This study \\
\hline \multirow[t]{2}{*}{ NSP4 } & NSP4F & TAAAAGTTCTGTTCCGAGAGAG & This study \\
\hline & NSP4 722R & TTAAGACCGTTCCTTCCATTAAC & This study \\
\hline
\end{tabular}


(a) VP7

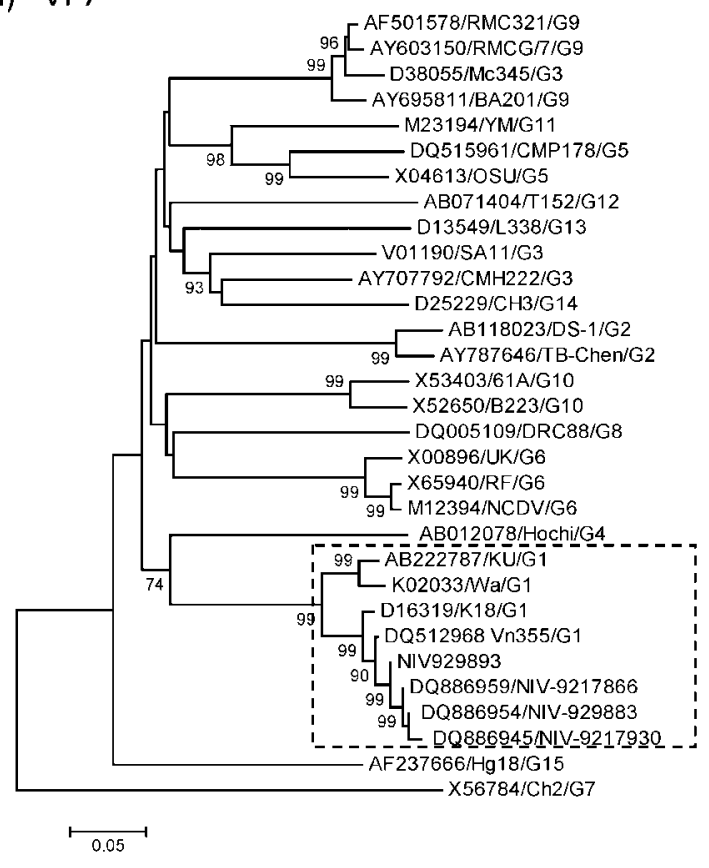

(b) VP4

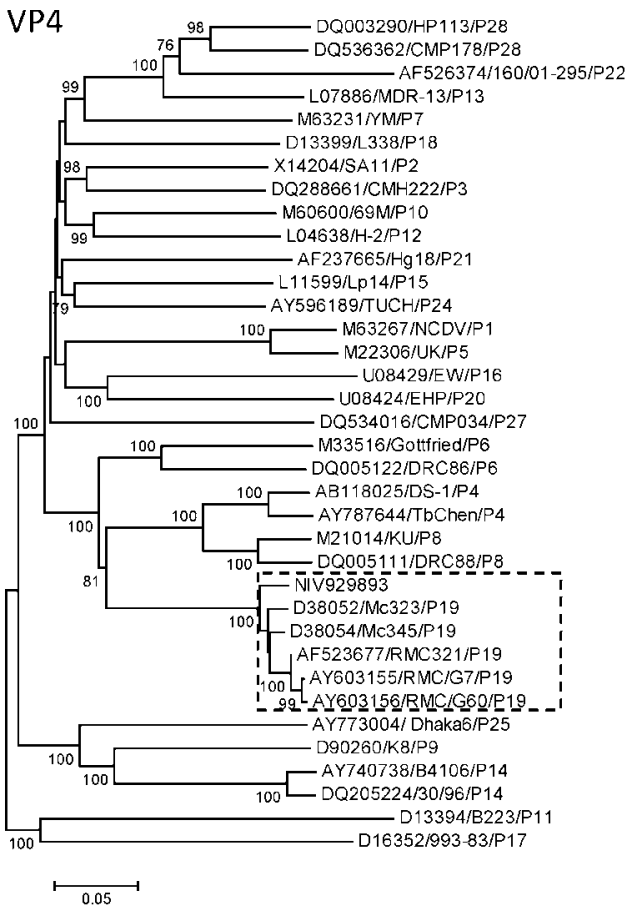

Fig. 1. Phylogenetic analysis of complete nucleotide sequences of VP7 (a) and VP4 (b) genes of rotavirus strain NIV929893. Clusters containing the NIV929893 strain are boxed, and for each strain the following data are given: GenBank accession number/strain name/genotype.

generally species-specific; however, cross-species transmission has been described in several studies (Okada et al., 2000; Varghese et al., 2004). The segmented nature of the rotavirus genome and a close genetic relationship between human and animal rotavirus strains favours generation of reassortants during mixed infection resulting from two different strains. The present study reports characterization of one such reassortant, G1P[19], which caused infection in a human.

Table 2. Comparative nucleotide and amino acid sequence identities of strain NIV929893 with other rotavirus strains

$\mathrm{NA}$, Sequence information not available. High nucleotide and amino acid identities are indicated in bold.

\begin{tabular}{|lcccc|}
\hline \multirow{2}{*}{ Strain } & \multicolumn{4}{c|}{ Nucleotide/amino acid identities (\%) } \\
\cline { 2 - 5 } & VP7 & VP4 & VP6 & NSP4 \\
\hline G1P[8]/KU & $\mathbf{9 2 . 5 / 9 6 . 4}$ & $77.2 / 73.6$ & $\mathbf{9 1 . 1 / 9 8 . 2}$ & $90.1 / 93.1$ \\
G2P[4]/TB-Chen & $73.1 / 76.3$ & $76.4 / 72.1$ & $80.8 / 92.4$ & $82.3 / 83.4$ \\
G5P[7]/OSU & $75.4 / 77.0$ & NA & $81.2 / 93.7$ & $94.4 / 96.6$ \\
G11P[7]/YM & $73.7 / 79.1$ & $71.8 / 59.7$ & $82.3 / 93.5$ & $91.8 / 94.9$ \\
G9P[19]/RMC321 & $76.2 / 79.8$ & $97.3 / 98.2$ & $82.0 / 93.5$ & $97.0 / 97.7$ \\
G9P[19]/RMC/G7 & $75.8 / 78.9$ & $\mathbf{9 7 . 4 / 9 8 . 8}$ & $82.3 / 93.2$ & $\mathbf{9 8 . 4 / 9 9 . 4}$ \\
G3P[19]/Mc345 & $75.5 / 75.8$ & $96.7 / 98.2$ & NA & NA \\
\hline
\end{tabular}

Globally, rotaviruses of the G1-G4, G9, P[4] and P[8] genotypes have been found to be a common cause of rotavirus diarrhoea in humans. G1 is the most commonly found genotype in human rotavirus infections. Although the combination of G1 with $\mathrm{P}[8]$ is well known worldwide, the combination of G1 with other P types has also been reported (Santos \& Hoshino, 2005).

$\mathrm{P}[19]$, a rare genotype, was first described for a porcine rotavirus strain, 4F, with G3 specificity (Burke et al., 1994). Subsequently, G3P[19] was isolated from faecal specimens of piglets with diarrhoea in Thailand (Maneekarn et al., 2006; Theamboonlers et al., 2008). However, in human infection, $\mathrm{P}[19]$ was identified with G9 strains from Thailand and India (Okada et al., 2000; Varghese et al., 2004). The study presented here documents for the first time, to our knowledge, the presence of $\mathrm{P}[19]$ specificity in association with G1.

In addition to the binary classification based on VP7 and VP4 genes, which display multiple combinations of G and $\mathrm{P}$ types, rotaviruses are also classified on the basis of the less diverse VP6 and NSP4 genes (Iturriza-Gòmara et al., 2003). VP6 is a major structural protein that interacts with the outer structural proteins VP4 and VP7 and the core protein VP2, whilst NSP4 is a non-structural protein that has been described as a receptor for VP6 during viral morphogenesis (Iturriza-Gòmara et al., 2003; Varghese et al., 2004). Among human rotaviruses, VP6 associates mainly with two subgroup specificities, SGI and SGII, 

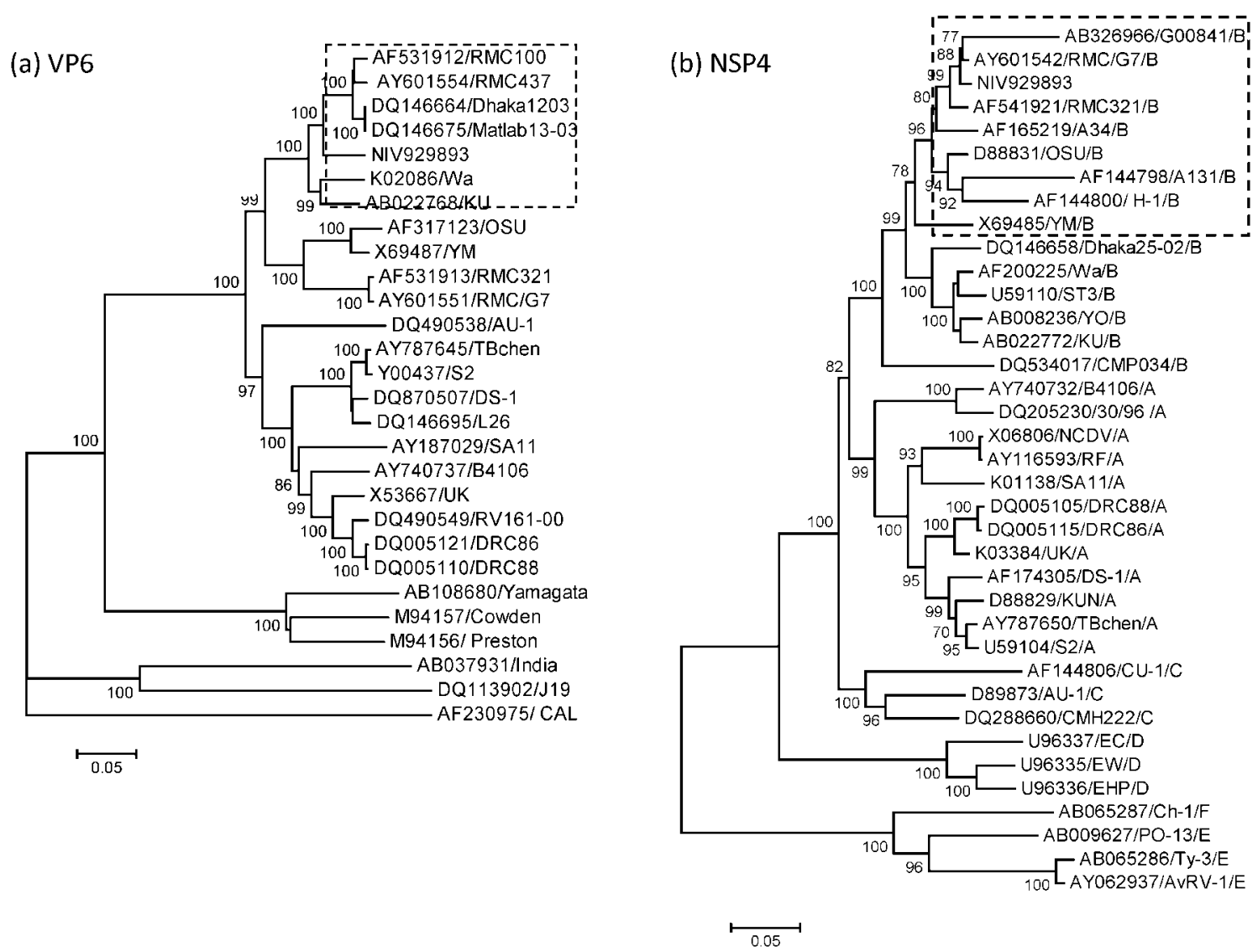

Fig. 2. Phylogenetic analysis of complete nucleotide sequences of the VP6 (a) and NSP4 (b) genes of rotavirus strain NIV929893. Clusters containing the NIV929893 strain are boxed, and for each strain the following data are given: GenBank accession number/strain name/genotype.

whilst NSP4 is restricted to two (A and B) of the six genotypes A-F (Iturriza-Gòmara et al., 2002). In a study conducted on rotavirus strains isolated from humans, it was suggested that both VP6 and NSP4 genes were linked to each other in common and reassortant rotavirus strains with $100 \%$ linkage (Iturriza-Gòmara et al., 2003). Accordingly, SGI of VP6 occurs in association with NSP4 genotype A, whilst SGII of VP6 associates with NSP4 genotype B. However, evidence of a VP6 gene related to bovine and human SGI strains, and a porcine NSP4 gene of genotype B has been documented for porcine group A rotavirus strains HP113 and HP140 (Ghosh et al., 2007).

In the present study, a VP6 gene with SGII specificity and an NSP4 gene of genotype B were identified in strain NIV929893. Interestingly, phylogenetic analysis of the deduced amino acid sequences of these genes showed a human origin for the VP6 gene and a porcine origin for the NSP4 gene. Thus, the findings of this study suggest that the linkage between the NSP4 genotype and VP6 subgroup appears to be vital in group A rotaviruses that cause infections in humans. Although the reassortment resulted from independently segregated genes, a combination of VP6
SGII and NSP4 genotype B was maintained in the recovered human strain, NIV929893. Independent segregation of VP6 and NSP4 genes has been reported previously in asymptomatic rotavirus infections (Banerjee et al., 2007).

To conclude, studies on the diversity of human rotavirus VP7, VP4, VP6 and NSP4 genes are of ecological importance and can provide insight into the mechanism involved in rotavirus evolution, interspecies transmission and exchange of genetic material during reassortment. The present study provides novel information on the occurrence of the unusual human rotavirus strain G1P[19] and direct evidence to support the interspecies transmission and reassortment of human and porcine rotaviruses in nature. Identification of such novel rotavirus reassortant strains is of epidemiological importance and can lead to serious implications regarding rotavirus vaccine development and implementation.

\section{ACKNOWLEDGEMENTS}

We thank Dr A. C. Mishra, Director, National Institute of Virology, Pune, India, for his constant support. 


\section{REFERENCES}

Banerjee, I., Iturriza-Gomara, M., Rajendran, P., Primrose, B., Ramani, S., Gary, J. J., Brown, D. W. \& Kang, G. (2007). Molecular characterization of $\mathrm{G} 11 \mathrm{P}[25]$ and $\mathrm{G} 3 \mathrm{P}[3]$ human rotavirus strains associated with asymptomatic infections in south India. J Med Virol 79, 1768-1774.

Burke, B., McCrae, M. A. \& Desselberger, U. (1994). Sequence analysis of two porcine rotaviruses differing in growth in vitro and in pathogenicity: distinct VP4 sequences and conservation of NS53, VP6 and VP7 genes. J Gen Virol 75, 2205-2212.

Ciarlet, M., Liprandi, F., Conner, M. E. \& Estes, M. K. (2000). Species specificity and interspecies relatedness of NSP4 genetic groups by comparative NSP4 analysis of animal rotaviruses. Arch Virol 145, 371-383.

Estes, M. K. (2001). Rotaviruses and their replication. In Fields Virology, 4th edn, pp. 1747-1785. Edited by D. M. Knipe \& P. M. Howley. Philadelphia: Lippincott Williams \& Wilkins.

Gentsch, J. R., Laird, A. R., Bielfelt, B., Griffin, D. D., Banyai, K., Ramachandran, M., Urasawa, S., Hasegawa, A., Urasawa, T. \& other authors (2005). Serotype diversity and reassortment between human and animal rotavirus strains: implications for rotavirus vaccine programs. J Infect Dis 192, S146-S159.

Ghosh, S., Varghese, V., Samajdar, S., Bhattacharya, S. K., Kobayashi, N. \& Naik, T. N. (2007). Evidence for independent segregation of the VP6- and NSP4-encoding genes in porcine group A rotavirus G6P[13] strains. Arch Virol 152, 423-429.

Gouvea, V., Glass, R. I., Woods, P., Taniguchi, K., Clark, H. F., Forrester, B. \& Fang, Z. Y. (1990). Polymerase chain reaction amplification and typing of rotavirus nucleic acid from stool specimens. J Clin Microbiol 28, 276-282.

Greig, S. L., Berriman, J. A., O’Brien, J. A., Taylor, J. A., Bellamy, A. R., Yeager, M. J. \& Mitra, A. K. (2006). Structural determinants of rotavirus subgroup specificity mapped by cryo-electron microscopy. $J$ Mol Biol 356, 209-221.

Grimwood, K. \& Kirkwood, C. D. (2008). Human rotavirus vaccines: too early for the strain to tell. Lancet 371, 1144-1145.

Horie, Y., Masamune, O. \& Nakagomi, O. (1997). Three major alleles of rotavirus NSP4 proteins identified by sequence analysis. J Gen Virol 78, 2341-2346.

Ito, H., Sugiyama, M., Masubuchi, Y., Mori, Y. \& Minamoto, N. (2001). Complete nucleotide sequence of a group A avian rotavirus genome and a comparison with counterparts of mammalian rotaviruses. Virus Res 75, 123-138.

Iturriza-Gòmara, M., Wong, C., Blome, S., Desselberger, U. \& Gray, J. (2002). Molecular characterization of VP6 genes of human rotavirus isolates: correlation of genogroups with subgroups and evidence of independent segregation. J Virol 76, 6596-6601.

Iturriza-Gòmara, M., Anderton, E., Kang, G. \& Gallimore, C. (2003). Evidence for genetic linkage between the gene segments encoding NSP4 and VP6 proteins in common and reassortant human rotavirus strains. J Clin Microbiol 41, 3566-3573.

Kumar, S., Tamura, K., Jacobsen, I. B. \& Nei, M. (2004). MEGA3: integrated software for Molecular Evolutionary Genetics Analysis and sequence alignment. Brief Bioinform 5, 150-163.

Maneekarn, N., Khamrin, P., Chan-it, W., Peerakome, S., Sukchai, S., Pringprao, K. \& Ushijima, H. (2006). Detection of rare G3P[19] porcine rotavirus strains in Chiang Mai, Thailand, provides evidence for origin of the VP4 genes of Mc323 and Mc345 human rotaviruses. J Clin Microbiol 44, 4113-4119.
Martella, V., Ciarlet, M., Baselga, R., Arista, S., Elia, G., Lorusso, E., Bányai, K., Terio, V., Madio, A. \& other authors (2005). Sequence analysis of the VP7 and VP4 genes identifies a novel VP7 gene allele of porcine rotaviruses, sharing a common evolutionary origin with human G2 rotaviruses. Virology 337, 111-123.

Matthijnssens, J., Rahman, M., Martella, V., Xuelei, Y., De Vos, S., De Leener, K., Ciarlet, M., Buonavoglia, C. \& Van Ranst, M. (2006). Full genomic analysis of human rotavirus strain B4106 and lapine rotavirus strain 30/96 provides evidence for interspecies transmission. J Virol 80, 3801-3810.

Matthijnssens, J., Ciarlet, M., Heiman, E., Arijs, I., Delbeke, T., McDonald, S. M., Palombo, E. A., Iturriza-Gòmara, M. I., Maes, P. \& other authors (2008). Full genome-based classification of rotaviruses reveals a common origin between human Wa-like and porcine rotavirus strains and human DS-1-like and bovine rotavirus strains. J Virol 82, 3204-3219.

Mori, Y., Borgan, M. A., Ito, N., Sugiyama, M. \& Minamoto, N. (2002). Diarrhoea inducing activity of avian rotavirus NSP4 glycoproteins, which differ greatly from mammalian rotavirus NSP4 glycoproteins in deduced amino acid sequence, in suckling mice. J Virol 76, 58295834.

Nakagomi, O., Ohshima, A., Aboudy, Y., Shif, I., Mochizuki, M., Nakagomi, T. \& Gotlieb-Stematsky, T. (1990). Molecular identification by RNA-RNA hybridization of a human rotavirus that is closely related to rotaviruses of feline and canine origin. J Clin Microbiol 28, 1198-1203.

Okada, J., Urasawa, T., Kobayashi, N., Taniguchi, K., Hasegawa, A., Mise, K. \& Urasava, S. (2000). New P serotype of group A human rotavirus closely related to that of a porcine rotavirus. J Med Virol $\mathbf{6 0}$, 63-69.

Santos, N. \& Hoshino, Y. (2005). Global distribution of rotavirus serotypes/genotypes and its implication for the development and implementation of an effective rotavirus vaccine. Rev Med Virol 15, 29-56.

Solberg, O. D., Hasing, M. E., Trueba, G. \& Eisenberg, J. N. (2009). Characterization of novel VP7, VP4, and VP6 genotypes of a previously untypeable group A rotavirus. Virology 385, 58-67.

Theamboonlers, A., Bhattarakosol, P., Chongsrisawat, V., Sungkapalee, T., Wutthirattanakowit, N. \& Poovorawan, Y. (2008). Molecular characterization of group A human rotaviruses in Bangkok and Buriram, Thailand during 2004-2006 reveals the predominance of G1P[8], G9P[8] and a rare G3P[19] strain. Virus Genes 36, 289-298.

Thompson, J. D., Higgins, D. G. \& Gibson, T. J. (1994). CLUSTAL W: improving the sensitivity of progressive multiple sequence alignment through sequence weighting, position-specific gap penalties and weight matrix choice. Nucleic Acids Res 22, 4673-4680.

Urasawa, S., Hasegawa, A., Urasawa, T., Taniguchi, K., Wakasugi, F., Suzuki, H., Inouye, S., Pongprot, B., Supawadee, J. \& other authors (1992). Antigenic and genetic analyses of human rotaviruses in Chiang Mai, Thailand: evidence for a close relationship between human and animal rotaviruses. J Infect Dis 166, 227-234.

Varghese, V., Das, S., Singh, N. B., Kojima, K., Bhattacharya, S. K., Krishnan, T., Kobayashi, N. \& Naik, T. N. (2004). Molecular characterization of a human rotavirus reveals porcine characteristics in most of the genes including VP6 and NSP4. Arch Virol 149, 155172.

Zade, J. K., Chhabra, P. \& Chitambar, S. D. (2009). Characterization of VP7 and VP4 genes of rotavirus strains: 1990-1994 and 2000-2002. Epidemiol Infect 137, 936-942. 